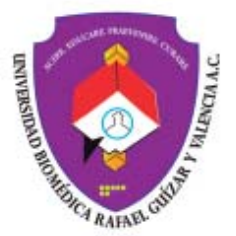

Vol. 8, Núm. 2

Julio-Diciembre 2021. pp. 89-95

doi: $10.35366 / 103087$

Información general actualizada

\title{
COVID-19: manifestaciones neurológicas más frecuentes y poco diagnosticadas
}

\author{
COVID-19: Most frequent and undiagnosed neurological manifestations \\ Francisco Aguilar Rebolledo, * Artemio López García ${ }^{\ddagger}$
}

\section{RESUMEN}

Introducción: Desde diciembre de 2019 se ha presentado una vertiginosa propagación de lo que hoy conocemos como enfermedad por coronavirus SARS-CoV-2 o COVID-19, denominado así por la Organización Mundial de la Salud (OMS) en marzo de 2020. Objetivo: Informar de las manifestaciones neurológicas del COVID-19. Resultados: Los síntomas en su inicio fueron principalmente respiratorios, sin embargo, cada vez han sido más evidentes los signos y síntomas neurológicos asociados a este virus, tales como dolor de cabeza, náuseas, vómito, encefalopatía, encefalitis, enfermedad vascular cerebral (EVC), anosmia, ageusia, crisis epilépticas, alteración de pares craneales, neuropatía periférica (síndrome de Guillain-Barré) con amiotrofia neuromuscular y rabdomiólisis. Los mecanismos de afectación neurológica de la COVID-19 se atribuyen a dos tipos de invasión: la directa (por las propiedades neurotrópicas del virus) y la invasión indirecta (derivados del estado proinflamatorio, procoagulante, alteraciones metabólicas y la desregulación del sistema inmune). Conclusiones: A pesar de que la incidencia de estas complicaciones neurológicas sean subdiagnosticadas, el aumento de la morbimortalidad nos permitirá tomar decisiones oportunas que impacten en la prevención del proceso neurodegenerativo de los pacientes con COVID-19.

Palabras clave: COVID-19, SARS-CoV-2, síntomas neurológicos, cefalea, amiotrofia.

\section{ABSTRACT}

Introduction: Since December 2019 there has been a dizzying spread of what we now know as coronavirus disease SARS-CoV-2 or COVID-19, named for the world health organization (WHO) in March 2020. Objective: Report the neurological manifestations of COVID-19. Results: Initially, the symptoms were mainly respiratory, however, neurological signs and symptoms associated with this virus have been increasingly evident, such as headache, nausea, vomiting, encephalopathy, encephalitis, cerebrovascular disease, anosmia, ageusia, seizures, cranial nerve alteration, peripheral neuropathy, Guillain-Barre syndrome, neuromuscular amyotrophy and rhabdomyolysis. The mechanisms of neurological involvement of COVID-19 are attributed to two types of invasion; direct (due to the neurotropic properties of the virus) and indirect invasion (derived from the pro-inflammatory and procoagulant state, metabolic alterations and dysregulation of the immune system). Conclusions: Despite the incidence of these neurological complications, the increase in morbidity and mortality will allow us to make timely decisions that impact the prevention of the neurological morbidity and mortality process in patients with COVID-19.

Keywords: COVID-19, SARS-CoV-2, neurological symptoms, headache, amyotrophy.

* Rector, Universidad Biomédica Rafael Guízar y Valencia, Xalapa, Veracruz, México, Director Clínica Universitaria, Centro Integral de Medicina Avanzada (CIMA). * Clínica Universitaria Centro Integral de Medicina Avanzada (CIMA).

Correspondencia:

Académico M. en C. Dr. Francisco Aguilar Rebolledo

E-mail: fran_aguilar_invest@yahoo.com.mx

Recibido: 11/08/2021. Aceptado: 28/09/2021.

Citar como: Aguilar RF, López GA. COVID-19: manifestaciones neurológicas más frecuentes y poco

diagnosticadas. Plast Restaur Neurol. 2021;8 (2): 89-95. https://dx.doi.org/10.35366/103087

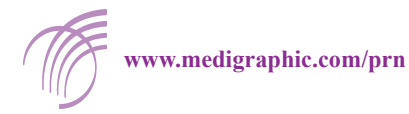




\section{INTRODUCCIÓN}

La enfermedad por coronavirus (COVID-19) producida por el SARS-CoV-2 ha sido un reto para los servicios de salud en todo el mundo. Los coronavirus son una familia de virus que afectan principalmente al sistema respiratorio humano, pero que también pueden extenderse al sistema nervioso central (SNC). Las epidemias o pandemias previas de coronavirus incluyen el síndrome respiratorio agudo severo (SRAS), en 2002 y el síndrome respiratorio del Medio Oriente (MERS) en $2012{ }^{1}$

En diciembre de 2019, una serie de casos de neumonía de causa desconocida fueron reportados en Wuhan, China. ${ }^{2}$ Se determinó por análisis genético en muestras de estos pacientes que se trataba de un nuevo coronavirus, al que se le denominó SARS-CoV-2 y a la enfermedad relacionada con éste, COVID-19. Debido a su alta transmisibilidad se extendió rápidamente por todo el mundo. ${ }^{2}$ La Organización Mundial de la Salud (OMS) la declaró como pandemia en abril de $2020 .{ }^{3}$

Hoy en México, para el 03 de noviembre de 2021 se reporta lo siguiente: total de casos $3,807,211$; casos activos estimados 70,132; el total de casos sospechosos es de 146,962 y 288,365 fallecidos. El porcentaje de vacunación poblacional es de $47.9 \%{ }^{4}$

Con el curso creciente de la actual pandemia de COVID-19, reportes de manifestaciones neurológicas asociadas a este virus han surgido y con afectación mundial. Se recuerda que se deben seguir las recomendaciones de la Secretaría de Salud. La epidemia no ha terminado. ${ }^{5}$

La Organización Mundial de la Salud (OMS) y la Secretaría de Salud de México declararon la epidemia como urgencia de salud pública y han pedido que se sigan las siguientes recomendaciones: conservar la sana distancia 1.5 metros, uso obligado del cubrebocas, lavarse las manos cuantas veces sea necesario, siguiendo los seis tiempos del lavado, usar alcohol o gel al $70 \%$ y sanitizar los espacios cerrados.

Objetivo: revisión de las complicaciones neurológicas de los coronavirus, y en particular del SARS-CoV-2 o COVID-19.

\section{Etiopatogenia}

Los coronavirus son virus ARN monocatenarios de sentido positivo, que albergan el genoma más grande entre los virus de ARN conocidos actualmente, con una longitud de genoma de aproximadamente 26-32 kb. Las partículas de virus teñidas muestran una forma típica de corona con un diámetro de 80-120 nm. ${ }^{6}$

Por otra parte, varios análisis han demostrado que el SARS-CoV-2 se une al receptor de membrana de la enzima convertidora de angiotensina II (ECA-II), a través de una estructura viral denominada proteína $S$; la entrada a las células produce la infección. EI ECA-II ha sido identificado en los neumocitos tipo II y en otras estirpes celulares. Estudios experimentales en ratones han demostrado una amplia distribución del ECA-II en las neuronas de los núcleos del tallo cerebral, involucrados en la regulación de la función cardiorrespiratoria, y de áreas como en la corteza motora y el núcleo rafe. ${ }^{7}$ Después de la entrada del SARS-CoV-2 en la célula, la producción de citoquinas proinflamatorias (por ejemplo, interleucina 1, interferón- $\gamma$, la proteína atrayente de monocitos 1 , etcétera) activaría la respuesta inflamatoria T Helper 1 (Th1). La gravedad de esta enfermedad estaría relacionada con esta «tormenta de citoquinas». ${ }^{8}$

\section{Neurotropismo del SARS-CoV-2}

Por otro lado, un hecho relevante es la expresión alta de receptores de ECA-II que tiene el cerebro, lo que podría implicar que la penetración de SARS-CoV-2 sea alta en el sistema nervioso. Es probable que la ruta de ingreso del virus sea a través del nervio olfatorio, sin embargo, está la posibilidad de la vía hemática, aunque más alejada debido a la presencia de la barrera hematoencefálica. ${ }^{7,8}$

Existe un informe reciente de encefalitis asociada a COVID-19, con detección de ARN del SARS-CoV-2 en el líquido cefalorraquídeo (LCR). ${ }^{9}$

\section{Manifestaciones neurológicas}

Los virus respiratorios pueden penetrar en el SNC (neuroinvasión), afectar tanto a neuronas como células gliales (propiedad conocida como neurotropismo) e inducir diversas patologías neurológicas (neurovirulencia). La hipótesis sobre las propiedades de neuroinvasión y neurovirulencia del SARS-CoV-2 se basa en la siguiente evidencia (Figura 1):

1. Plausibilidad biológica extrapolada de la afectación del SNC por otros virus respiratorios.

2. Evidencia de daño neurológico por coronavirus en otras especies.

3. Modelos animales de infección del SNC por coronavirus humanos. 
Figura 1:

Potenciales vías de neuroinvasión del SARS-CoV-2 al sistema nervioso central. Tomada de: Bio-Render.

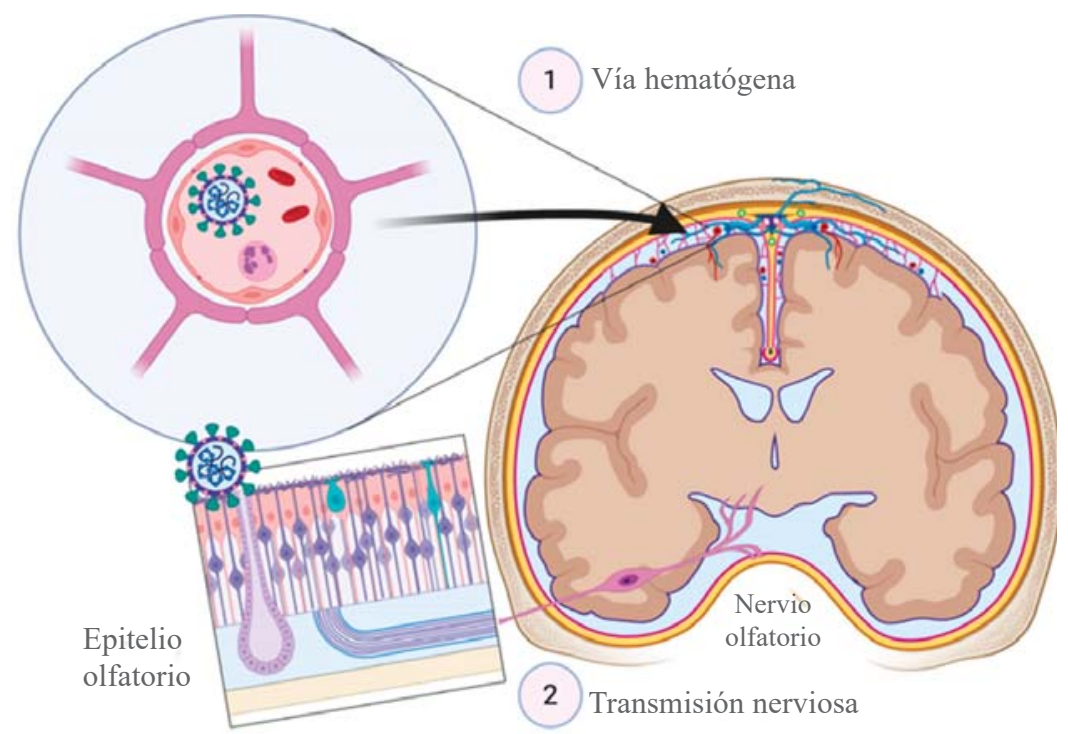

4. Existencia de complicaciones neurológicas por otros coronavirus.

En un estudio descriptivo reciente de 214 pacientes con COVID-19, 78 (36.4\%) pacientes presentaron manifestaciones neurológicas tales como:

1. Mareos

2. Cefalea

3. Alteración del estado de conciencia

4. Enfermedad cerebrovascular

5. Ataxia

6. Convulsiones

7. Pérdida del gusto (ageusia)

8. Pérdida del olfato (anosmia)

9. Alteraciones visuales

10. Dolor neuropático

11. Mialgias

La COVID-19 puede causar compromiso neurológico a través de una lesión directa o indirecta. La primera se debería a la replicación viral directa en el sistema nervioso y la segunda sería consecuencia de la activación de la cascada inflamatoria, las alteraciones tóxico-metabólicas, la desregulación inmunológica y sus mecanismos inmunomediados. ${ }^{10}$

Las manifestaciones neurológicas se podrían clasificar en tres categorías:

1. Manifestaciones del sistema nervioso central (SNC) (mareos, dolor de cabeza, alteración de la conciencia, enfermedad vascular cerebral (EVC), ataxia y convulsiones).
2. Manifestaciones del sistema nervioso periférico (SNP) (alteración del gusto, alteración del olfato, discapacidad visual y dolor neuropático).

3. Manifestaciones musculares (miositis y rabdomiólisis). ${ }^{11}$

\section{MANIFESTACIONES EN EL SISTEMA NERVIOSO CENTRAL (Figura 2)}

El SARS-CoV-2 puede causar encefalitis, enfermedad cerebrovascular o encefalopatía tóxico-metabólica y presentarse con trastornos del estado de conciencia. En autopsias de pacientes con COVID-19 se han encontrado signos de edema cerebral y en la consulta cefalea de inicio en $16-28 \%$ de los casos.

Una cefalea que aparece por primera vez puede indicar una relación temporal y estrecha con la infección.

La COVID-19 puede predisponer a los pacientes a trombosis arterial y venosa y probablemente sea resultado del estado de hipercoagulabilidad secundario a la cascada inflamatoria y a la disfunción endotelial encontrado en pacientes graves y con factores de riesgo cardiovascular. ${ }^{11}$

Se debe realizar un adecuado abordaje clínico y electrofisiológico en pacientes con COVID-19 que presenten esta manifestación clínica. ${ }^{11,12}$

\section{MANIFESTACIONES EN EL SISTEMA NERVIOSO PERIFÉRICO}

Las alteraciones del SNP más comunes son hipogeusia (5-16\%) e hiposmia-anosmia (5-21\%). Otros estudios indican que la alteración a nervios craneales fue de 
$71 \%$, algunas de ellas incluso pudiendo ocurrir antes de las manifestaciones pulmonares (alteraciones del I y IX par craneal con pérdida transitoria de olores y sabores). ${ }^{10}$ Se han reportado varias series de casos de neuropatía como el síndrome de Guillain-Barré (SGB) en pacientes con COVID-19, en distintos centros hospitalarios.

\section{MANIFESTACIONES MUSCULARES}

Asimismo, en la serie de 214 pacientes se describió lesión muscular en $10.7 \%$ de los pacientes, éstos en su mayoría fueron casos severos y tenían en la clínica síntomas de dolor muscular acompañada de niveles altos de creatinfosfocinasa (CPK), lo que sugeriría que el nuevo coronavirus también produce miopatía, rabdomiólisis y amiotrofia. Sin embargo, no se ha podido aislar al virus del tejido muscular. ${ }^{6,7}$

En este mismo estudio retrospectivo de 214 pacientes, $36.4 \%$ presentó algún tipo de manifestación neurológica que fue categorizada como:

1. Afectación del SNC (24.8\%).

2. Afectación al SNP (12.7\%).

3. Afectaciones musculoesqueléticas (10.7\%).
Los síntomas neurológicos más comunes fueron mareo (36 casos), cefalea (28 casos), hipogeusia (12 casos) e hiposmia (cinco casos). Los síntomas neurológicos fueron más frecuentes en pacientes con COVID-19 grave $(45.5 \%), 6,7,13$

El compromiso neurológico por este virus puede ser originado por una lesión directa, por hipoxia o por respuesta inmune, produciendo así encefalopatía, encefalitis y/o encefalopatía necrosante aguda hemorrágica. Estas últimas primordialmente se presentan en infecciones graves, pero se deben tener en cuenta también en casos leves a moderados. ${ }^{14}$

\section{MANIFESTACIONES NEUROLÓGICAS: LONG-HAULERS}

Un long hauler es una persona que contrajo la enfermedad COVID-19 y que continúa presentando síntomas muchas semanas después, mucho después de que la mayoría de los demás pacientes se hayan recuperado. Los médicos y los investigadores no están seguros de qué causa este fenómeno. Algunos long haulers se han organizado en grupos de apoyo, otros han participado en investigaciones dirigidas por pacientes sobre la enfermedad. ${ }^{13}$

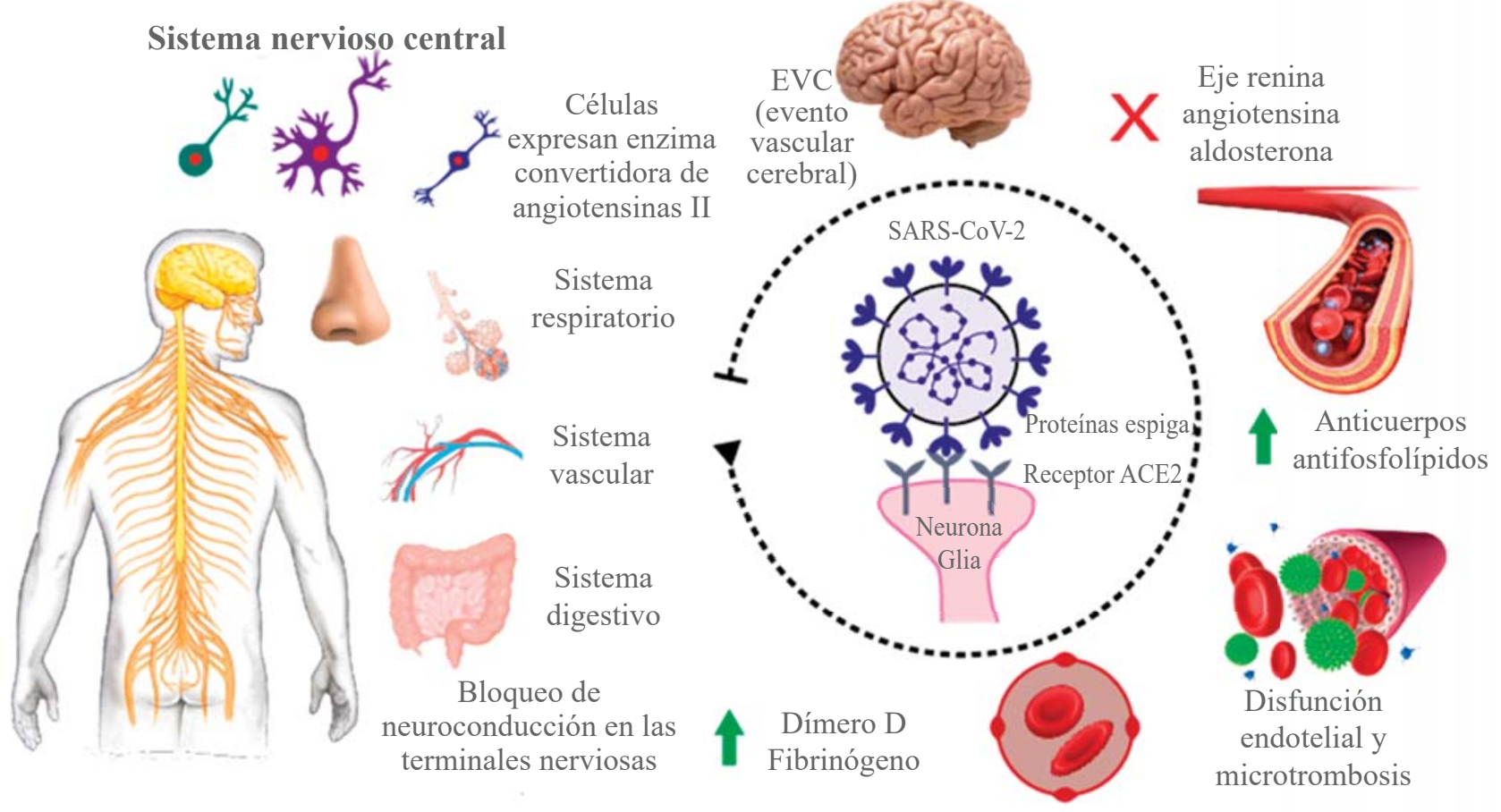

Figura 2: Manifestaciones del sistema nervioso central y sus complicaciones sistémicas. 


\section{COMPLICACIONES CEREBROVASCULARES}

Dentro de las complicaciones cerebrovasculares se puede presentar el accidente vascular cerebral (AVC) isquémico en 5\% de los pacientes, la trombosis cerebral de los senos venosos en 1\%; y AVC hemorrágico en $0.5 \%$. Los factores de riesgo de sufrir un AVC fueron:

1. Edad avanzada (edad media: 71.6 años), padecer COVID-19 grave, tener una historia previa de hipertensión, diabetes o EVC previa.

2. Actividad procoagulante marcada (aumento de la proteína $C$ reactiva y el dímero $D)$. La mortalidad fue de $38 \%$.

El síndrome de tormenta de citocinas puede ser otro factor de riesgo de enfermedad cerebrovascular. ${ }^{11}$

\section{SÍNDROME DE GUILLAIN-BARRÉ}

El síndrome de Guillain-Barré (SGB) se convirtió en la manifestación neurológica autoinmune principal, desencadenada por el SARS-CoV-2. Estudios del líquido cefalorraquídeo han evidenciado aumento de proteínas (124 $\mathrm{mg} / \mathrm{dL}$ ) y ausencia de células. El examen neurofisiológico muestra latencias disminuidas y ausencia de ondas F, lo que apunta a una forma de SGB desmielinizante.

Se denomina enfermedad desmielinizante porque el daño principal se ve en la mielina de los nervios periféricos, lo que genera paresia, debilidad muscular, hasta parálisis ascendente de presentación bilateral. Si los daños neuronales alcanzan a los nervios diafragmáticos, el paciente presenta desde dificultad respiratoria leve hasta necesidad de asistencia ventilatoria invasiva. El tratamiento del SGB mejora con el uso de gammaglobulina intravenosa (Ig-IV), sobre todo en etapas iniciales, vigilando la capacidad respiratoria, el manejo sintomático y el soporte ventilatorio en caso de requerirse. ${ }^{10}$

\section{MIASTENIA GRAVIS Y COVID-19}

Hay evidencia de que el virus SARS-CoV-2 puede penetrar en el SNC, en algunos casos generando Miastenia gravis y neuropatía periférica.

Se desarrolla una diplopía con presencia de anticuerpos contra el receptor de acetilcolina, con mejoría clínica en pocos días hasta su desaparición completa. La causa es autoinmune con tropismo positivo sobre la unión neuromuscular con base en un fenómeno de mimetismo molecular. ${ }^{12}$

\section{AFECTACIÓN DE NERVIOS CRANEALES Y COVID-19}

El SARS-CoV-2 se puede transmitir por contacto directo o indirecto con las membranas y mucosas de los ojos, boca, nariz, por lo que el tracto respiratorio no debe considerarse la única vía de transmisión.

Caso clínico. Con afectación ocular. Mujer de 49 años que refiere presencia de fiebre, astenia, mialgias y cefaleas de tres días de evolución. El estudio (PCR) para SARS-CoV-2 fue positivo. El cuadro clínico, la IRM con proceso inflamatorio en el nervio óptico izquierdo y seno cavernoso derecho, y la radiografía de tórax reveló neumonía multifocal (Figura 3).

\section{NEUROPATÍA PERIFÉRICA Y COVID-19}

La polineuropatía desmielinizante inflamatoria crónica es una forma de polineuropatía que, como el síndrome de Guillain-Barré, provoca debilidad muscular que evoluciona durante más de ocho semanas posteriores al contagio del SARS-CoV-2.

$\mathrm{Al}$ igual que el SGB, tiene su origen en una reacción autoinmunitaria que daña la vaina de mielina que envuelve los nervios periféricos.

En este trastorno, la debilidad empeora de forma continua durante un periodo de más de ocho semanas posteriores al contagio. Algunos reportes mencionan que suele aparecer en los pacientes «long-haulers» hasta cinco a seis meses después de la infección activa del virus. ${ }^{9}$

En esta complicación, la debilidad es más irregular, afecta los dos lados del cuerpo de forma diferente con asimetrías notorias y también es posible que progrese con más lentitud, comparado con el SGB. ${ }^{14}$

\section{IMPLICACIONES PARA EL DIAGNÓSTICO Y EL TRATAMIENTO}

La respuesta de anticuerpos sigue un patrón típico, y los anticuerpos IgM desaparecen pasadas 12 semanas de la infección, mientras que los anticuerpos IgG específicos antiproteína viral $\mathrm{S}$ y $\mathrm{N}$ persisten un tiempo más prolongado, por lo que desempeñan un papel protector. El diagnóstico clínico de la COVID-19 se basa en la historia epidemiológica, las manifestaciones clínicas y la confirmación de la exposición al virus. ${ }^{8,14}$ La fisiopatología hasta el momento indica neurovirulencia y neurotropismo. Síntomas generales como fiebre y dolor neuromuscular, respiratorios 

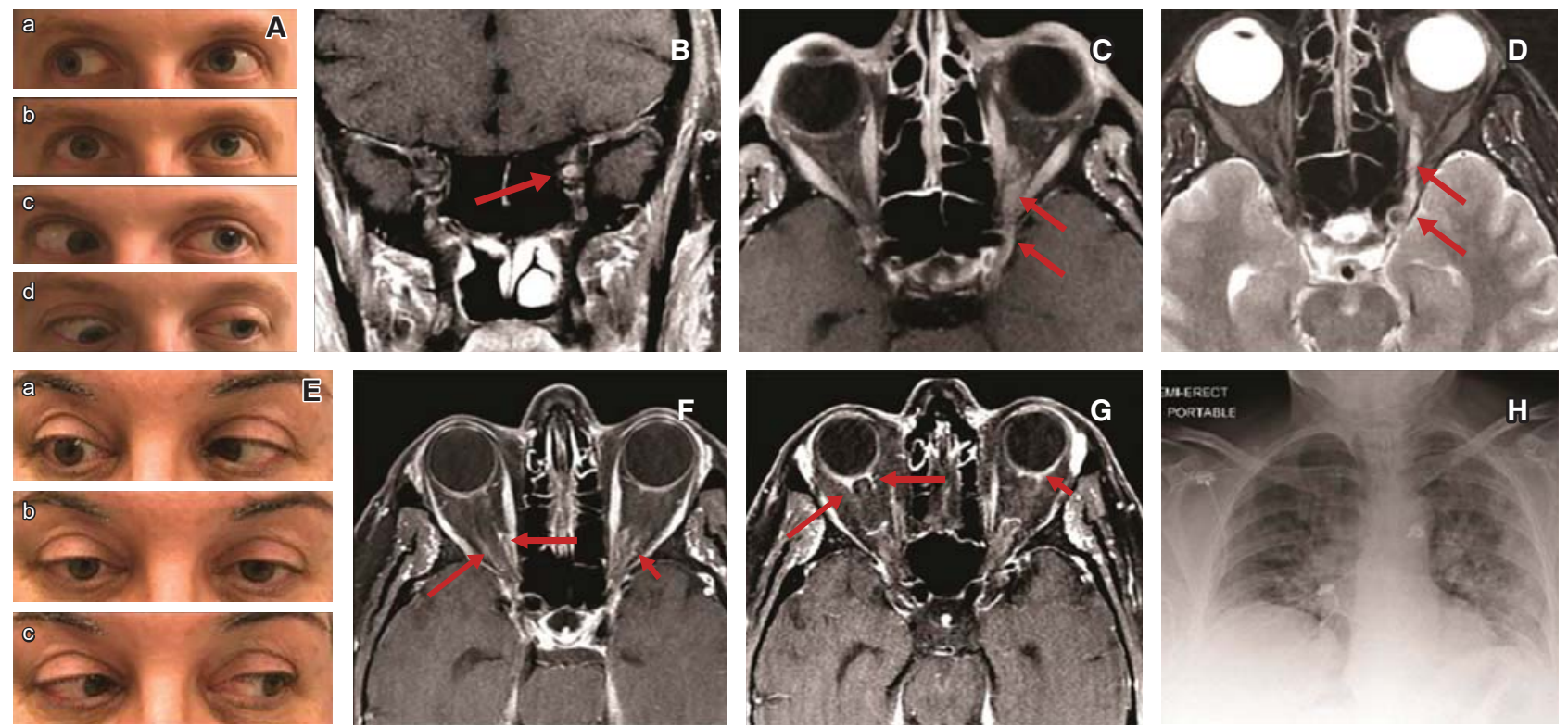

Figura 3: A-H) Examen motor de los ojos. A) Movimientos oculares y parálisis oculomotora. A.a) Limitación de la aducción del ojo izquierdo. A.d) Depresión: incapacidad para la mirada conjugada hacia abajo. En A.b se observó hipertropía del ojo izquierdo en la mirada primaria. En A.c incapacidad para la abducción del ojo izquierdo. B) En la imagen por resonancia magnética (IRM) en T1 por coronal postcontraste existe realce del nervio motor ocular común (III par craneal izquiedo flechas). C) IRM axial postcontraste con engrosamiento del músculo recto lateral izquierdo y el nervio óptico izquierdo. D) IRM T2 en corte axial con engrosamiento del recto interno y del III par craneal izquierdo. E.a) Parálisis del recto lateral a la mirada conjugada a la derecha. Parálisis oculomotora del recto lateral del ojo derecho. E.b) Endotropia a la mirada primaria. E.c) Mirada conjugada a la izquierda sin afectación. F y G) IRM axial en T1 flair. Engrosamiento de ambos nervios ópticos con reforzamiento de la cápsula de Tenon (flechas). H) Radiografía de tórax simple infiltrado pulmonar difuso.

como cuadro gripal con tos, y neurológicos con cefalea, son manifestaciones inespecíficas de la infección viral por SARS-CoV-2. Pero en algunos casos podrían orientar a patologías más graves, como meningitis o encefalitis.

\section{CONCLUSIONES}

La existencia y el advenimiento de una pandemia que desbordó los servicios de salud ha dejado una alta sospecha de que existen factores virales y mutaciones de genes específicos que aumentan la virulencia de SARS-CoV-2 al igual que factores asociados al huésped como la edad avanzada, comorbilidades e inmunosupresión. Las manifestaciones neurológicas de COVID19 ocurren por invasión directa (por las propiedades neurotrópicas del virus) y por mecanismos indirectos (derivados del estado proinflamatorio, procoagulante, las alteraciones metabólicas y la desregulación del sistema inmune). Por otro lado, la incidencia real de las complicaciones neurológicas y su tipo al igual que la gravedad son frecuentes y a la vez inciertos, por lo que futuros estudios epidemiológicos y de investigación deberán adelantarse para esclarecer dudas de nuestro conocimiento actual y poder ayudar temprana y oportunamente a las personas con afectación neurológica.

\section{REFERENCIAS}

1. Asadi-Pooya AA, Simani L. Central nervous system manifestations of COVID-19: a systematic review. J Neurol Sci. 2020; 413: 1-4.

2. Reporte del día 14 de Julio de 2021 de los casos activos, sospechosos y la población fallecida en México. Secretaría de Salud 2021.

3. Hamid S, Mir MY, Rohela GK. Novel coronavirus disease (COVID-19): a pandemic (epidemiology, pathogenesis and potential therapeutics). New Microbes New Infect. 2020; 35: 100679. doi: 10.1016/j.nmni.2020.100679.

4. Matías-Guiu UJ, Gomez-Pinedo P, Montero-Escribano P, Gomez-Iglesias J, Porta-Etessam J, Matias-Guiu A. ¿Es esperable que haya cuadros neurológicos por la pandemia por SARS-CoV-2? Neurología. 2020; 35: 170-175. doi: 10.1016/j. nrl.2020.03.001.

5. Filatov A, Sharma P, Hindi F, Espinosa SP. Neurological complications of coronavirus disease (COVID-19): encephalopathy. Cureus. 2020; (3): e7352. doi: 10.7759/cureus.7352.

6. Poyiadji N, Shahin G, Noujaim D, Stone M, Patel, Brent GS. COVID19-associated acute hemorrhagic necrotizing encephalopathy: 
CT and MRI features. Radiology. 2020; 296: 1527-1315. doi: org/10.1148/radiol.2020201187.

7. Salas AJ, Sánchez GC, Rodríguez SR. Características clínicas y comorbilidades asociadas a mortalidad en pacientes con COVID-19 en Coahuila (México). Revista Clínica Española. 2020; 3: 151-157.

8. Von Oertzen TJ. COVID-19-neurologists stay aware! Eur J Neurol. 2020; 27: 14-36.

9. Alberti $P$, Beretta $S$, Piatti $M$, Karantzoulis A, Piatti ML, Santoro $\mathrm{P}$ et al. Guillain-Barré syndrome related to COVID-19 infection. Neuroinflamm. 2020; 7 (4): e741. doi: org/10.1212/ NXI.000000000000074.

10. Hess DC, Eldahsahn W, Rutkowski E. COVID-19-related stroke. Transl Stroke Res. 2020; 7 : 1-4.

11. Camelo-Filho AE, Silva AMS, Estephan EP, Zambon AA, Mendonca RH, Souza PVS et al. Myasthenia gravis and COVID-19: clinical characteristics and outcomes. Front Neurol. 2020; 11: 1053. doi: org/10.3389/fneur.2020.01053.

12. Dinkin M, Gao V, Kahan J, Bobker S, Simonetto M, Wechsler P et al. COVID-19 presenting with ophthalmoparesis from cranial nerve palsy. Neurology. 2020; 95 (5): 221-223. doi: https://doi. org/10.1212/WNL.0000000000009700

13. Rubin R. As their numbers grow, COVID-19 "long haulers" stump experts. JAMA. 2020; 324 (14): 1381-1383. doi: org/10.1007/ s12975-020-00818-9.

14. Abdelnour L, Abdalla ME, Babiker S. COVID-19 infection presenting as motor peripheral neuropathy. J Formos Med Assoc. 2020; 119 (6): 1119-1120. doi: 10.1016/j.jfma.2020.04.024.

Declaración de ética: Se cumplieron los requerimientos éticos.

Financiamiento: Este estudio no fue apoyado por subvenciones.

Conflicto de intereses: Los autores declaran que la investigación se llevó a cabo en ausencia de relaciones comerciales o financieras que pudieran interpretarse como un posible conflicto de intereses. 